\title{
Improvement of Risk Assessment from Space Radiation Exposure for Future Space Exploration Missions
}

\author{
Myung-Hee Y. Kim ${ }^{1,2}$, Bill Atwell ${ }^{3}$, Artem L. Ponomarev ${ }^{1,4}$, Hatem Nounu ${ }^{1,5}$, Hesham \\ Hussein $^{1,5}$, and Francis A. Cucinotta ${ }^{1}$ \\ ${ }^{1}$ NASA Johnson Space Center, Houston, TX 77058, USA \\ ${ }^{2}$ Wyle Laboratories, Inc., Houston, TX 77058, USA \\ ${ }^{3}$ The Boeing Company, Houston, TX 77058, USA \\ ${ }^{4}$ Universities Space Research Association, Houston, TX 77058, USA \\ ${ }^{5}$ University of Houston, Houston, TX 77058, USA
}

\begin{abstract}
Protecting astronauts from space radiation exposure is an important challenge for mission design and operations for future exploration-class and long-duration missions. Crew members are exposed to sporadic solar particle events (SPEs) as well as to the continuous galactic cosmic radiation (GCR). If sufficient protection is not provided the radiation risk to crew members from SPEs could be significant. To improve exposure risk estimates and radiation protection from SPEs, detailed variations of radiation shielding properties are required. A model using a modern $\mathrm{CAD}$ tool ProE ${ }^{\mathrm{TM}}$, which is the leading engineering design platform at NASA, has been developed for this purpose. For the calculation of radiation exposure at a specific site, the cosine distribution was implemented to replicate the omnidirectional characteristic of the $4 \pi$ particle flux on a
\end{abstract}


surface. Previously, estimates of doses to the blood forming organs (BFO) from SPEs have been made using an average body-shielding distribution for the bone marrow based on the computerized anatomical man model (CAM). The development of an 82-point body-shielding distribution at BFOs made it possible to estimate the mean and variance of SPE doses in the major active marrow regions. Using the detailed distribution of bone marrow sites and implementation of cosine distribution of particle flux is shown to provide improved estimates of acute and cancer risks from SPEs.

\section{Introduction}

NASA follows radiation exposure limits (Cucinotta and Durante 2006) and implements appropriate risk mitigation measures to ensure that humans can safely live and work in the space radiation environment anywhere, anytime. In the context of the radiation protection principle of "as low as reasonably achievable" (ALARA), "safely" means that acceptable risks are not exceeded during crew members' lifetimes, where "acceptable risks" include limits on post-mission and multi-mission consequences. In design of future space missions and for the implementation of health protection measures, accurate predictions of astronaut's radiation exposure are required. In the simulation of lunar radiation interactions of large SPEs, radiation transport properties of shielding materials and astronaut's body tissues were calculated by the BRYNTRN code system (Cucinotta et al. 1994). In the previous work for future space mission design (Kim et al. 2005), a typical shield configuration has been approximated as a spherical structure and one of sensitive sites of blood-forming organ (BFO) was taken as an average body- 
shielding distribution of the bone marrow using the computerized anatomical man (CAM) model based on the astronaut body geometry (Billings and Yucker 1973). With these approximations, the overall exposure levels at the sensitive sites were reduced to within the current exposure limits from a large SPE by adding effective polyethylene shielding to various spacecraft thicknesses.

In the development of an integrated strategy to provide astronauts maximal radiation protection with consideration of the mass constraints of space missions, the focus of the current work was to provide several considerations in detail for the improvement of risk assessment. Detailed variations of radiation shielding properties were modeled using a modern CAD tool ProE ${ }^{\mathrm{TM}}$ (2004), representing a significant improvement in shielding analysis because it provides an analysis tool on the identical platform of most engineering designs of space vehicles. Another consideration includes the correctly aligned geometries between human and vehicle at a specific exposure site and the correction of particle source to replicate the omnidirectional characteristic of the $4 \pi$ particle flux on a surface. Because the specific doses at various BFOs account for the considerable variations of proton fluences across marrow regions, an 82-point bodyshielding distribution at BFOs was developed and the mean and variance of SPE doses were made with detailed distributions of major active marrow regions of head and neck, chest, abdomen, pelvis, and thighs.

The current considerations are among many requirements that must be met to improve the estimation of effective doses for radiation cancer risks. By implementing the 
distribution of shielding properties, detailed directional risk assessment was visualized, which can guide the ultimate protection for risk mitigation inside a habitable volume during future exploration missions.

\section{Approach of Risk Assessment}

Space radiation is a large health concern for astronauts who are involved in space missions outside the Earth’s geomagnetic field. In addition to the continuous background exposure to GCR, sporadic exposure to SPEs present the most significant risk for short-

stay lunar missions ( $<90 \mathrm{~d}$ ). The risk of early effects is very small due to the reduction of dose-rates behind shielding ( $<1 \mathrm{cGy} / \mathrm{h})$ (Cucinotta and Durante 2006), however radiation sickness is a concern for extra-vehicular activities (EVAs) on the moon where shielding will be at a minimum. The physical compositions and intensities of historically large SPEs are routinely examined in sensitive astronaut tissues behind various shielding materials using the Baryon transport code, BRYNTRN (Cucinotta et al., 1994), to predict the propagation and interactions of the deep-space nucleons through various media. The radiation risk at the sensitive tissue sites and the effective dose were assessed with the transported properties of the shielding materials and the astronauts' body tissue. The representative shield configurations were assumed to be aluminum with spherical thickness for spacesuit and spacecraft. Body-shielding distributions at sensitive organ sites of astronaut surrounding a specific point were generated using the CAM model (Billings and Yucker, 1973). The point particle fluxes that are traversed the tissue equivalent material of water for 512 rays were calculated at a specific anatomical area 
inside a shield. Assessment of radiation risk at a specific organ or tissue was calculated with the point particle fluxes. The effective dose $(E)$, which is currently used for NASA operational radiation protection program, is the representative quantity of stochastic effects for human body, where the radiation quantities of individual organs or tissues are multiplied by their respective tissue weighting factors (ICRP60, NCRP116). Figure 1 shows the exposure levels in free space as a function of shielding thickness of a spherical configuration for aluminum and graphite from August 1972 SPE (King 1972).

Structural design and variations of material composition layers have been considered for the total integrated shielding calculations by utilizing CAMERA raytracing algorithm at several dose measurement locations for space shuttle and International Space Station lab module (Saganti et al. 2001). At each dose location, evenly spaced distributions of 512 rays over a $4 \pi$ solid angle were used for the point flux calculation of a given ambient radiation. In Table 1, the exposure estimates obtained from the ray-tracing are compared with the values at the average shielding thickness of each dosimetry locations (DLOCs) of space shuttle from August 1972 SPE. The latter values are taken from the spherical configuration in the Figure 1. It surely shows the big difference. The improved exposure estimates were made after accounting for the structural configuration by utilizing ray-tracing.

Table 1. Comparison of exposure estimates of ray-tracing with those at the average thickness of the 6 dosimetry locations of shuttle from August 1972 SPE.

\begin{tabular}{|l|l|l|l|}
\hline Shuttle & & Effective dose, cSv & $\begin{array}{c}\text { BFO dose at the average } \\
\text { BFO site, cGy-Eq }\end{array}$ \\
\hline
\end{tabular}




\begin{tabular}{|l|c|c|c|c|c|}
\hline $\begin{array}{l}\text { dosimetry } \\
\text { location }\end{array}$ & $\begin{array}{c}\bar{X}=\frac{1}{N} \sum X_{i}, \\
\begin{array}{c}\text { Average } \\
\text { shielding } \\
\text { thickness, g/cm }\end{array}\end{array}$ & $\begin{array}{c}E=\frac{1}{N} \sum E\left(X_{i}\right), \\
\text { With ray- tracing }\end{array}$ & $E(\bar{X})$ & $B=\frac{1}{N} \sum B\left(X_{i}\right)$, & $B(\bar{X})$ \\
\hline DLOC1 & 26.67 & 36.41 & 2.8 & 24.28 & 1.8 \\
\hline DLOC2 & 16.46 & 76.05 & 8.0 & 49.62 & 7.0 \\
\hline DLOC3 & 19.44 & 72.60 & 4.5 & 47.13 & 3.5 \\
\hline DLOC4 & 20.01 & 60.11 & 4.4 & 41.77 & 3.4 \\
\hline DLOC5 & 21.08 & 73.44 & 3.9 & 48.10 & 3.0 \\
\hline DLOC6 & 20.92 & 74.09 & 3.9 & 48.96 & 3.0 \\
\hline
\end{tabular}

\section{Structural Distribution Model Using ProETM}

Recognizing that polymeric materials have better shielding effectiveness with reduced mass constraint (Wilson et al. 1995), future exploratory-class spacecraft will be composed with various high-performance polymeric composites with enhanced material's property and multi-functionalities, while the basic spacecraft construction material has been aluminum. Since the low-energy proton spectra are attenuated rapidly with shielding, the important factors for determining the exposure levels at sensitive tissue sites are the mass distributions of the detailed structural shielding materials and the astronaut's body.

To quantify each directional shielding amount offered by material composition layers, a structural distribution model was developed to account for detailed spacecraft geometry by using CAD tool of ProE ${ }^{\mathrm{TM}}$ (2004). All of structural components and contents, such as various racks, equipments, and inner and outer shell materials of the exploratory-class spacecraft, were included into the model with the detailed atomic/molecular compositions, their bulk densities, and the linear dimensions for the 
ray-tracing calculation. Each ray evaluates the directional distribution of material intersections for space radiation propagation to a specific interior dosimetry evaluation point. Using the characteristic of shield property, which depends on the basic atomic/molecular and nuclear processes, the complexity of vector rays with actual materials is equated to the vector rays of a specified common spacecraft material, e.g. aluminum-equivalent, according to the following equation:

$T_{A l-e q}=T_{\text {Mat }} \times \frac{R_{A l}\left(p_{50 \mathrm{MeV}}\right)}{R_{\text {Mat }}\left(p_{50 \mathrm{MeV}}\right)}=X_{\text {Mat }} \times \rho_{\text {Mat }} \times \frac{R_{A l}\left(p_{50 \mathrm{MeV}}\right)}{R_{\text {Mat }}\left(p_{50 \mathrm{MeV}}\right)}$

Where

$T_{\text {Al-eq: }}$ Areal density of aluminum-equivalent, in $\mathrm{g} / \mathrm{cm}^{2}$

$T_{\text {Mat: }} \quad$ Areal density of a material, in $\mathrm{g} / \mathrm{cm}^{2}$

$X_{\text {Mat: }}$ Linear thickness of a material, in $\mathrm{cm}$

$R_{A l}\left(p_{50 \mathrm{MeV}}\right)$ : Range of $50 \mathrm{MeV}$ proton beam on aluminum, in $\mathrm{g} / \mathrm{cm}^{2}$

$R_{\text {Mat }}\left(p_{50 \mathrm{MeV}}\right)$ : Range of $50 \mathrm{MeV}$ proton beam on a target material, in $\mathrm{g} / \mathrm{cm}^{2}$

$r_{\text {Mat: }}$ Bulk density of a material , in $\mathrm{g} / \mathrm{cm}^{3}$

A new fully automated method uses complete list of actual materials for selection and allows the ray-tracings for the equivalent thickness of any given material at the userspecific dosimetry points for the evaluation of shielding. Figure 2 shows an example of the structural distribution model developed using ProE ${ }^{\mathrm{TM}}$. Figure 3 shows the integrated shielding thickness distributions at 4 different dosimetry locations obtained from this model. It surely shows inherent directional variation of shielding thickness by which hot spot can be easily pointed out in a habitable volume.

\section{Radiation Source Consideration}


For the principal goal of planetary radiation simulation at a critical site of human body inside a spacecraft, habitat, or spacesuit during EVA on lunar or Mars surface, the production of emitted ion spectra was predicted by solving the fundamental Boltzmann transport equation for the propagation and interaction of the deep-space nucleons and heavy ions through various media. The fully coupled, all energy, all particle simulation was made for given number of rays by using the new fully automated ray tracing model, in which detailed radiation shielding properties were fully accounted for each ray with each separate medium's thickness distribution along a ray surrounding at a specific position. Similarly, radiation point flux at a specific organ site was calculated with detailed body-shielding properties at the site of human body geometry using the CAM model based on the 50 percentile United States Air Force male in the standing position (Billings and Yucker, 1973).

When it comes to the angular description of incident particle on a specific location, until now it has been treated as an isotropic angular distribution:

$p(\mu)=$ constant

where $\mu$ is the cosine of the angle between the particle direction (the ray) and the surface normal (on the surface of a specific organ site). It is a common mistake to give the incident particles an isotropic angular distribution in an attempt to replicate the omnidirectional characteristic of a $4 \pi$ point flux. The appropriate method for describing a surface source of particles incident on a specific organ site is actually a cosine distribution:

$p(\mu)=\mu$ 
for a uniformly distributed source of particles at the site. In this way, energy deposited into the small volume site of an organ is correctly accounted for all the incident particles which are evenly spaced for the given number of rays over a $4 \pi$ solid angle.

The shielding distribution can be treated as randomly oriented for spacecraft and body organs or as a fixed alignment when evaluating organ doses inside spacecraft. Either case is an idealization of the actual motion of an astronaut inside a spacecraft or habitat. For the latter case, the fully coupled shielding properties at each direction between the integrated shielding by spacecraft and the body-shielding were correctly obtained only after their orientations were correctly aligned at a specific organ site. The improved organ dose assessment at a specific anatomical location was estimated with the correct point particle fluxes for given number of rays and the correctly coupled shielding thickness at each rays:

\section{Consideration of Active Bone Marrow Distributions}

The most critical organ site considered for radiation protection is BFO. It has been assumed as an average body-shielding distribution for the bone marrow based on CAM model. However, quantitative estimates of the active bone marrow in adults are quite distributed over several body regions as shown in Table 2 (Cristy, 1981). Therefore, the 82 specific BFO sites of the different active regions as shown in Figure 4 were accounted for the human body geometry using the CAM model (Atwell, 1994). Estimates of specific dose at various BFO sites have been shown large variations inside a typical equipment room of spacecraft (an aluminum sphere of $5 \mathrm{~g} / \mathrm{cm}^{2}$ thickness) on lunar surface as shown in figure 5 . The fact that considerable variance of doses across marrow 
sites was caused by the characteristic spectra of proton fluence at each site made the use of an average BFO doubtful. The variations will be further increased when the complexities of spacecraft distributions will be accounted, which is necessary for the accurate radiation risk assessment prediction and protection guide from the complex radiation fields and shielding distributions. The development of the 82-point BFO shielding distribution made it possible to estimate the mean and variance of SPE doses in the major active marrow regions of head and neck, chest, abdomen, pelvis, and thighs as shown in Figure 6. It will allow more accurate estimates of the marrow response to estimate the radiation risk of leukemia, which could be the dominant risk to astronauts from a major SPE (Cucinotta et al. 2006).

Table 2. Active marrow distributions in adults (age 40) calculated from anatomical data (Cristy, 1981)

\begin{tabular}{|l|l|}
\hline Body region & Marrow distribution \\
\hline Head and Neck & $12.2 \%$ \\
Chest (Upper Torso) & $26.1 \%$ \\
Abdomen (Mid Torso) & $24.9 \%$ \\
Pelvis (Lower Torso) & $33.4 \%$ \\
Thighs (Upper Legs) & $3.4 \%$ \\
Lower Legs & n/a \\
Arms & n/a \\
\hline
\end{tabular}

6. Results and discussion

For use in the effort to make accurate assessment of radiation doses to astronauts, which are required for planning of future exploration-class and long-duration space missions (Cucinotta and Durante 2006), a fully automated structural distribution model has been developed using a CAD tool of ProE ${ }^{\mathrm{TM}}$. Visual presentation of shielding thickness easily shows that the hot spots are existed for sensitive sites of tissue/organ inside a future spacecraft, while its overall configuration provides enough shielding from 
a SPE as shown in figure 3. With the directional shielding amounts, the results of organ dose quantities are shown in Table 3 at four different locations inside a spacecraft. We also implemented radiation source corrections: (1) cosine distribution for the angular description of incident particle on a specific site and (2) correct alignment of spacecraft and body for the coupled shielding properties for each rays. The results are shown in the same table in the column labeled as ‘Aligned orientation’. Finally, detailed directional risk assessment is visualized in figure 7 at a dosimetry location (DLOC1) inside a spacecraft. In this figure, the spacecraft is shown in a translucent view to reveal the exact dosimetry location in the left hand side, and the same directional dose assessment is separately shown in large view in the right hand side. This kind of visualization can guide the ultimate protection for risk mitigation inside a habitable volume during future exploration missions. It is easily noticed that top hatch of a spacecraft can provide the most shielding effect from SPE, while some area like window is the least. This rationale will help to develop many objective-oriented strategies, such as local shielding approaches, optimization of equipments/components as shields, and optimization of astronaut orientation.

Because of the characteristic spectra of primary solar protons of SPE, proton fluences and doses vary considerably across marrow regions. Detailed body-shielding distribution of 82 bone marrow sites were accounted for the active marrow regions, which faithfully reproduced the mean and the standard deviations of SPE doses in those regions. More accurate estimates of the marrow response will be used to estimate the radiation risk of leukemia from a major SPE (Cucinotta et al. 2006). The large variation 
in marrow doses has opposite results when considering acute risks versus the risk of leukemia. For the acute risk to the BFOs, the marrow with lower dose component is fully capable of replenishing the entire blood system. Therefore, knowledge of the variation is extremely important. For leukemia risk, a linear-quadratic dose response is found (NCRP 132). Therefore, the marrow regions with high doses are the concern since leukemia risk may arise from a large SPE condition where the quadratic component of the doseresponse comes into play.

In the current work, we made significant improvement of risk assessment with the several considerations. Many other requirements must be improved as future work for the risk assessment and protection of astronauts, which may include new definition of age and gender related tissue weighting factors, modified transport codes with neutrons produced inside spacecraft, improved space environmental projection models for mission planning, and using all detailed transport properties with the atomic properties of structural components by using parallel processing.

Table 3. Result of organ dose quantities by using the fully automated structural distribution model, and comparison with results from implementing radiation source correction at each ray (aligned orientation).

\begin{tabular}{|c|c|c|c|c|c|c|c|c|}
\hline & \multicolumn{8}{|c|}{ August 1972 SPE } \\
\hline & \multicolumn{4}{|c|}{ Random orientation } & \multicolumn{4}{|c|}{\begin{tabular}{|c|} 
Aligned orientation \\
\end{tabular}} \\
\hline & DLOC1 & DLOC2 & DLOC & $3 \overline{\mathrm{DLOC} 4}$ & DLOC1 & $1 \overline{\mathrm{DLOC} 2}$ & DLOC3 & DLOC4 \\
\hline X-coordinate, $\mathrm{cm}$ & 43.18 & -43.18 & 40.64 & -40.64 & 43.18 & -43.18 & 40.64 & -40.64 \\
\hline Y-coordinate, cm & 119.38 & 119.38 & 119.38 & 119.38 & 119.38 & 119.38 & 119.38 & 119.38 \\
\hline Z-coordinate, cm & 52.71 & 52.71 & -79.34 & -79.34 & 52.71 & 52.71 & -79.38 & -79.38 \\
\hline Al-Eq $x_{\text {avg }}, \mathrm{g} / \mathrm{cm}^{2}$ & 15.18 & 15.08 & 15.85 & 15.33 & 15.18 & 15.08 & 15.85 & 15.33 \\
\hline $\mathrm{X}_{\min }-\mathrm{x}_{\max }$ & 0 - & $0-$ & $0-$ & $0-$ & 0 - & $0-$ & $0-$ & 0 - \\
\hline
\end{tabular}




\begin{tabular}{|c|c|c|c|c|c|c|c|c|c|}
\hline & & 102.07 & 105.50 & 83.21 & 85.79 & 102.07 & 105.50 & 83.21 & 85.79 \\
\hline \multirow{15}{*}{$\begin{array}{l}\text { CAM } \\
\text { organ } \\
\text { dose, } \\
\text { cSv }\end{array}$} & Avg skin & 126.61 & 121.07 & 104.08 & 108.59 & 150.92 & 135.41 & 111.45 & 114.45 \\
\hline & Eye & 86.76 & 84.36 & 73.58 & 77.06 & 89.71 & 89.94 & 81.62 & 79.72 \\
\hline & Avg BFO & 16.91 & 16.82 & 15.2 & 15.88 & 18.14 & 18.20 & 16.05 & 15.98 \\
\hline & Stomach & 7.38 & 7.37 & 6.77 & 7.03 & 6.94 & 6.89 & 6.59 & 6.63 \\
\hline & Colon & 14.42 & 14.36 & 13.04 & 13.6 & 14.46 & 14.36 & 12.67 & 12.79 \\
\hline & Liver & 10.37 & 10.33 & 9.41 & 9.8 & 9.43 & 9.60 & 8.92 & 9.23 \\
\hline & Lung & 12.16 & 12.12 & 11.04 & 11.5 & 12.09 & 11.61 & 11.30 & 10.73 \\
\hline & Esophagus & 11.61 & 11.57 & 10.54 & 10.98 & 11.25 & 10.78 & 10.52 & 9.93 \\
\hline & Bladder & 7.54 & 7.53 & 6.9 & 7.17 & 7.64 & 7.25 & 6.98 & 6.84 \\
\hline & Thyroid & 18.39 & 18.31 & 16.55 & 17.28 & 18.55 & 18.15 & 16.47 & 16.79 \\
\hline & Chest & 72.23 & 70.58 & 61.85 & 64.83 & 74.88 & 73.95 & 67.60 & 66.37 \\
\hline & Gonads & 35.27 & 34.74 & 30.76 & 32.24 & 37.72 & 32.64 & 31.19 & 27.74 \\
\hline & Front brain & 29.54 & 29.32 & 26.31 & 27.53 & 28.72 & 27.60 & 25.32 & 25.32 \\
\hline & Mid brain & 16.2 & 16.15 & 14.68 & 15.3 & 15.52 & 15.56 & 14.05 & 15.03 \\
\hline & Rear brain & 28.93 & 28.72 & 25.79 & 26.98 & 27.49 & 27.96 & 24.98 & 27.84 \\
\hline \multicolumn{2}{|c|}{ Point dose eq, cSv } & 254.68 & 242.74 & 207.92 & 216.83 & 253.48 & 241.76 & 205.76 & 211.88 \\
\hline
\end{tabular}

Reference:

Atwell, W., 1994. Anatomical models for space Radiation Applications: An Overview. Adv. Space Res., 14(10), 415-422.

Billings, M.P., Yucker, W.R., 1973. The computerized anatomical man (CAM) model, NASA CR-134043.

Cristy, M., 1981. Active bone marrow distribution as a function of age in humans. Phys. Med. Biol., Vol. 26, No. 3, 389-400.

Cucinotta, F. A., Wilson, J. W., Badavi, F. F., 1994. Extension to the BRYNTRN code to monoenergetic light ion beams. NASA TP-3472. 
Cucinotta, F.A., Durante, M., 2006. Cancer risk from exposure to galactic cosmic rays: implications for space exploration by human beings, Lancet Oncology, 7, pp. 431-435.

Cucinotta, F. A., W. Atwell, Kim, M. Y., George, K. A., Ponomarev, A., Nikjoo, H., and Wilson, J. W., 2006. Prediction of leukemia risk to astronauts form solar particle events, $4^{\text {th }}$ International workshop on Space Radiation Research, June 5-9, 2006, Moscow, Russia.

International Commission on Radiobiological Protection (ICRP), 1991. 1990 Recommendations of the International Commission on Radiobiological Protection. ICRP Publication 60, Annals of the ICRP 21, Elsevier Science, New York.

Kim, M.Y., Hu, X., Cucinotta, F.A., 2005. Effect of shielding materials from SPEs on the lunar and Mars surface, AIAA 2005-6653.

King, J. H., August 1972 SPE spectra, unpublished records of a NASA workshop, correspondence dated October 24, 1972, from J. H. King (NASA Goddard Space Flight Center) to A. C. Hardy (NASA Johnson Space Center).

National Council on Radiation Protection and Measurements (NCRP), 1993. Limitation of exposure to ionizing radiation. NCRP Report No. 116, Bethesda, MD. 
National Council on Radiation Protection and Measurements (NCRP), 2000. Radiation protection guidance for activities in low-Earth orbit. NCRP Report No. 132, Bethesda, MD.

Pro/ENGINEER ${ }^{\circledR}$ Wildfire 2.0, Parametric Technology Corporation, March 2004.

Saganti, P. B., Zapp, E. N., Wilson, J. W., Cucinotta, F. A., visual Assessment of the Radiation Distribution in the ISS Lab Module, Physica Medica, XVII, Supplement 1, 106-112, 2001.

Wilson, J.W., Kim, M., Schimmerling, W., Badavi, F.F., Thibeault, S.A., Cucinotta, F.A., Shinn, J.L., and Kiefer, R., 1995. Issues in space radiation protection, Health Physics, 68, pp. 50-58. 


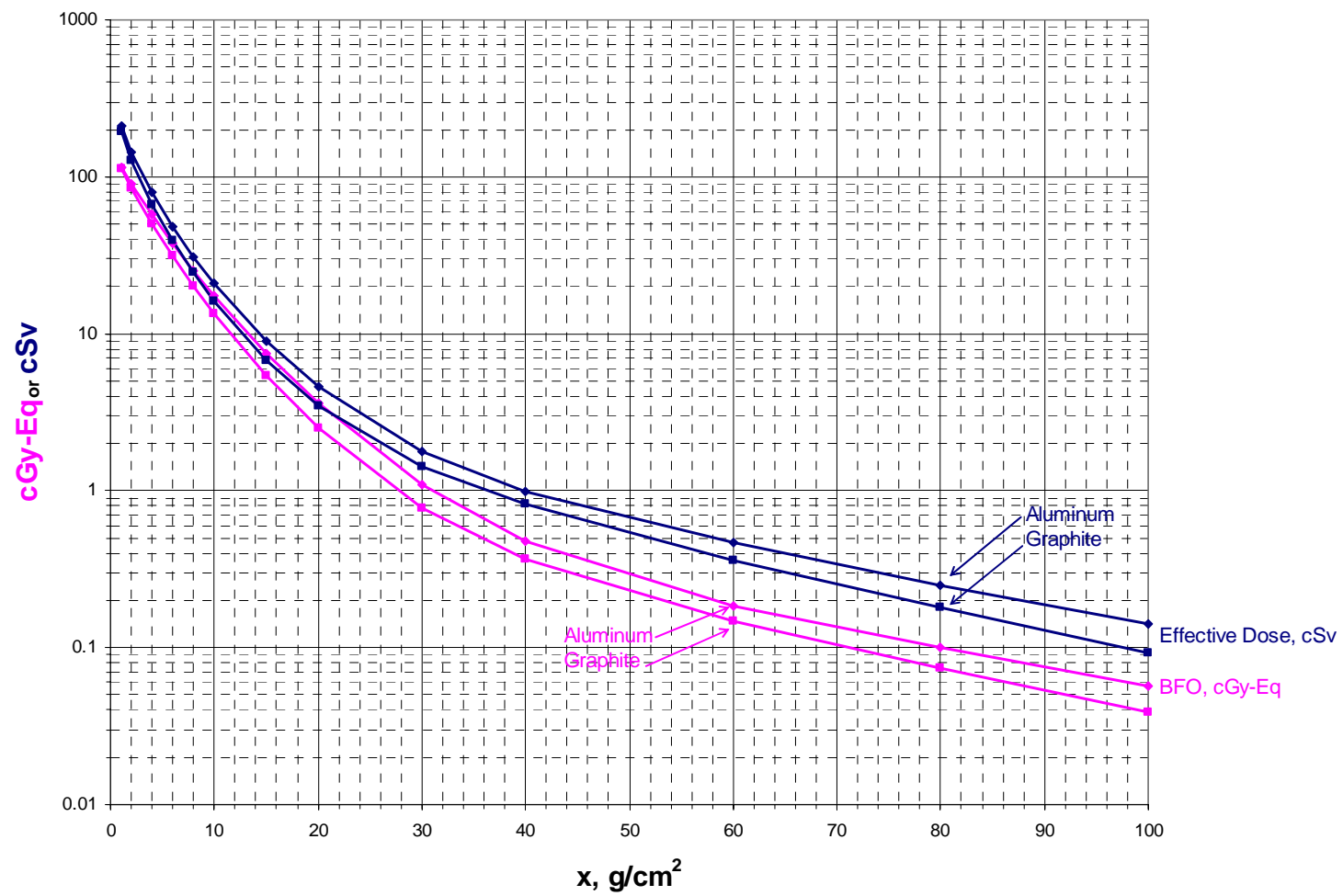

Figure 1. Effective dose and BFO dose behind aluminum and graphite shielding

materials in free space from August 1972 solar particle event. 


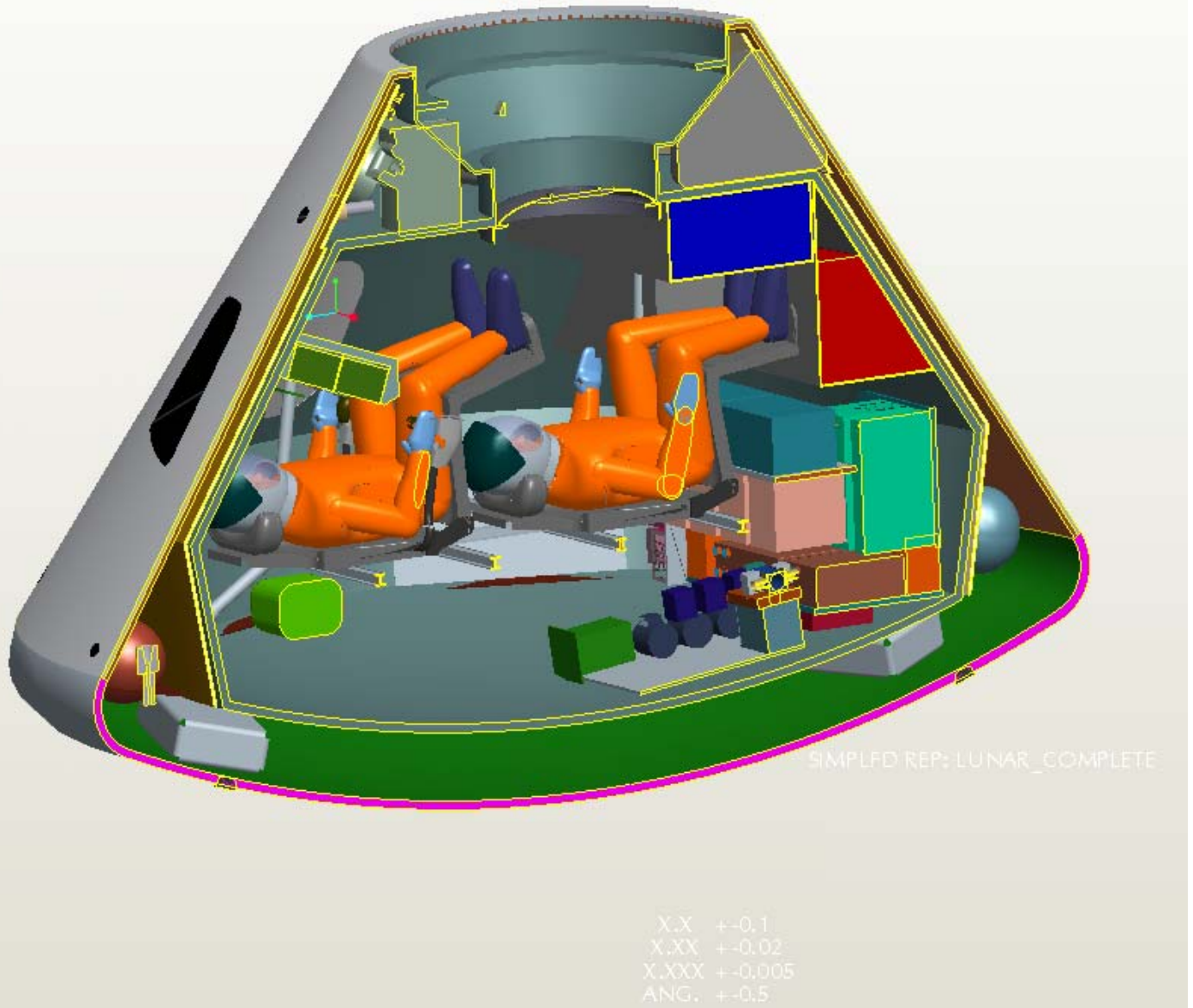

Figure 2. Structural distribution model of various composition layers for exploratoryclass spacecraft developed using ProE ${ }^{\mathrm{TM}}$. 

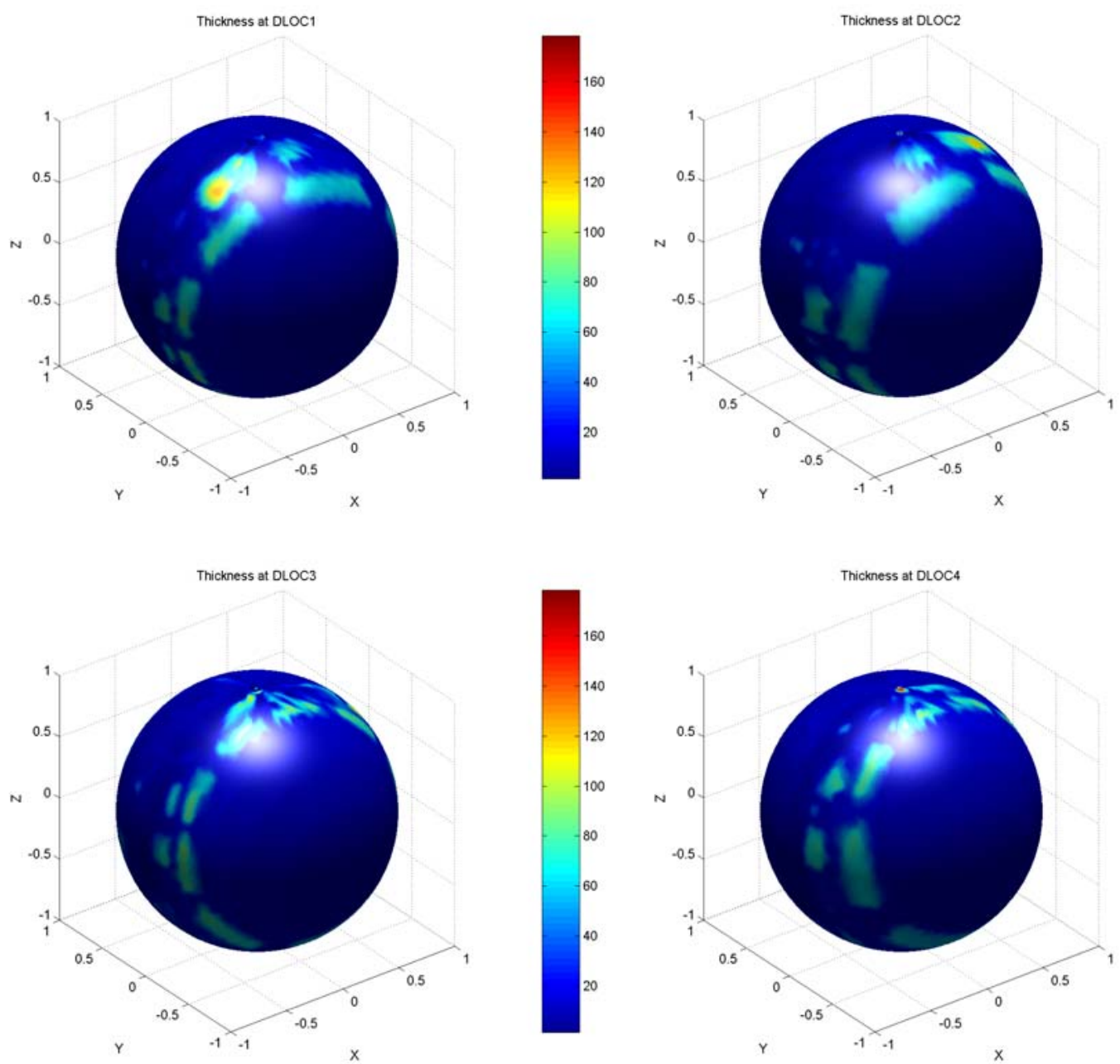

Figure 3. Shielding distributions at 4 different locations inside a spacecraft. 


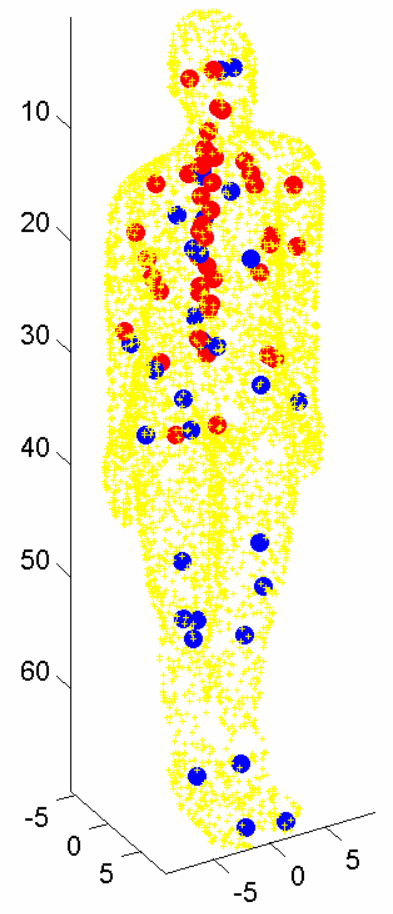

Figure 4. The 82-point BFO sites to cover the different active marrow regions. 


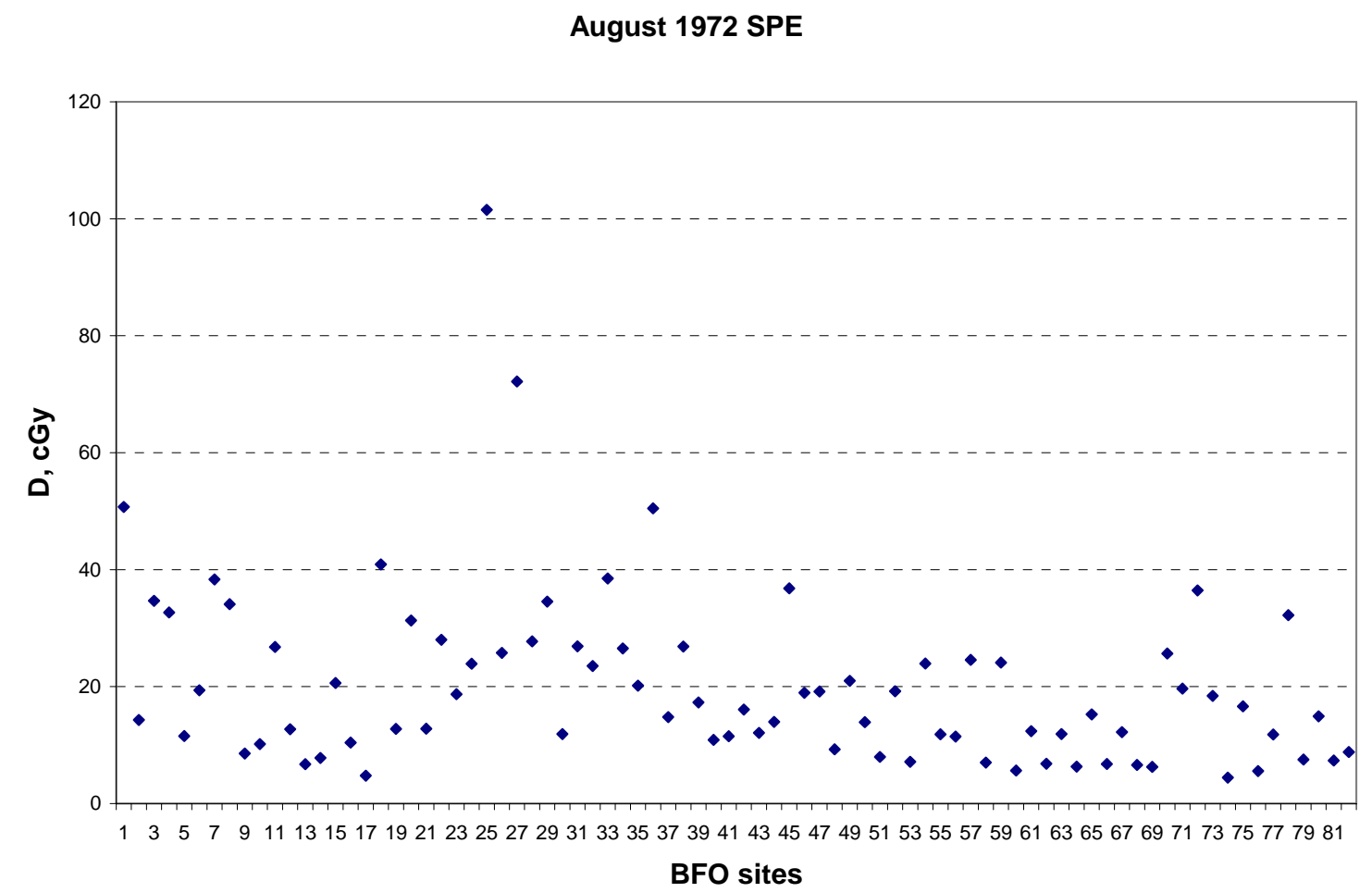

Figure 5. Absorbed dose distributions at $82 \mathrm{BFO}$ sites of astronaut inside a typical equipment room of spacecraft on lunar surface from August 1972 SPE. 


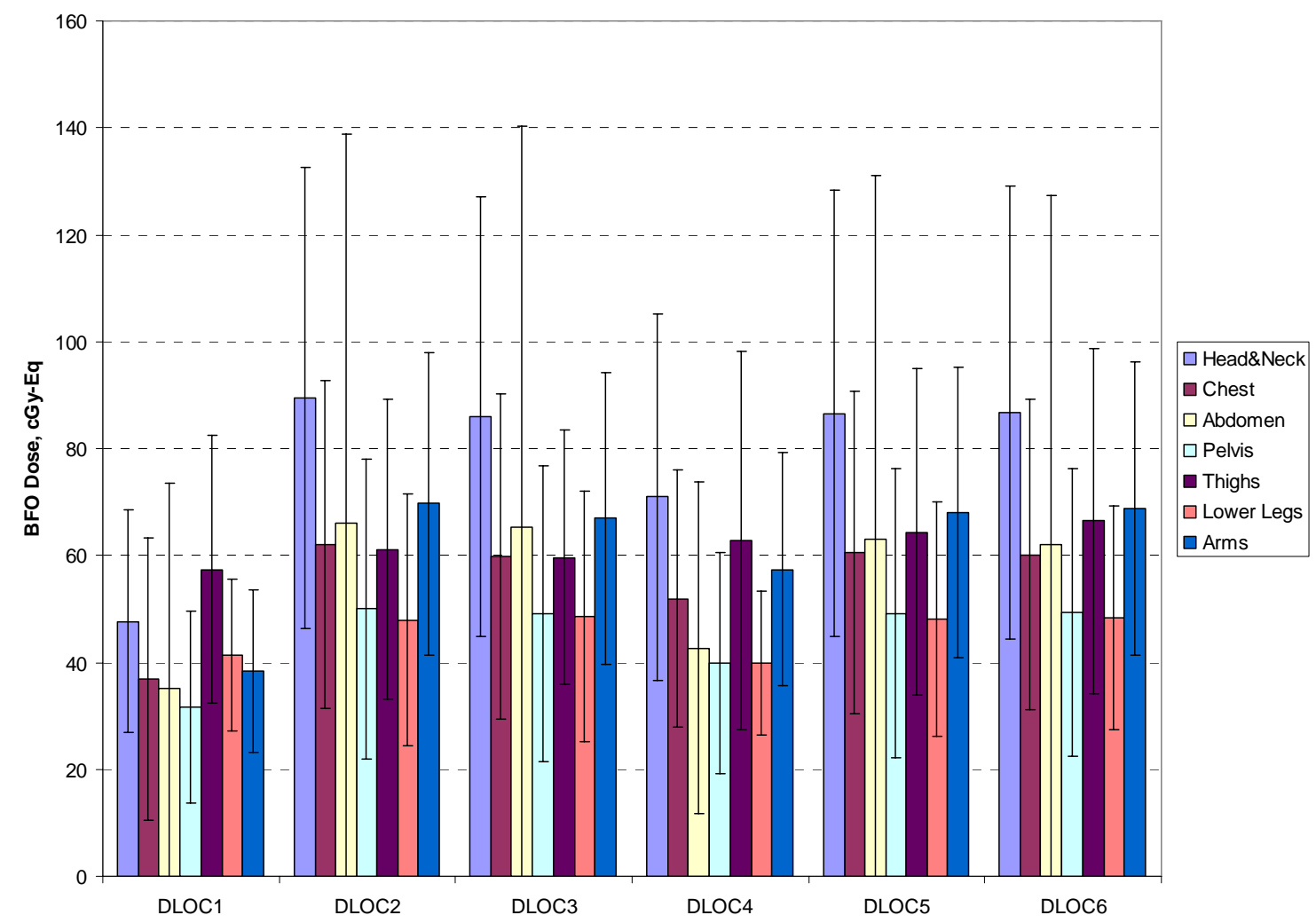

Figure 6. The average BFO doses and their standard deviations from August 1972 SPE for various body regions of active marrow sites located at 6 dosimetry locations (DLOCs) of space shuttle. 


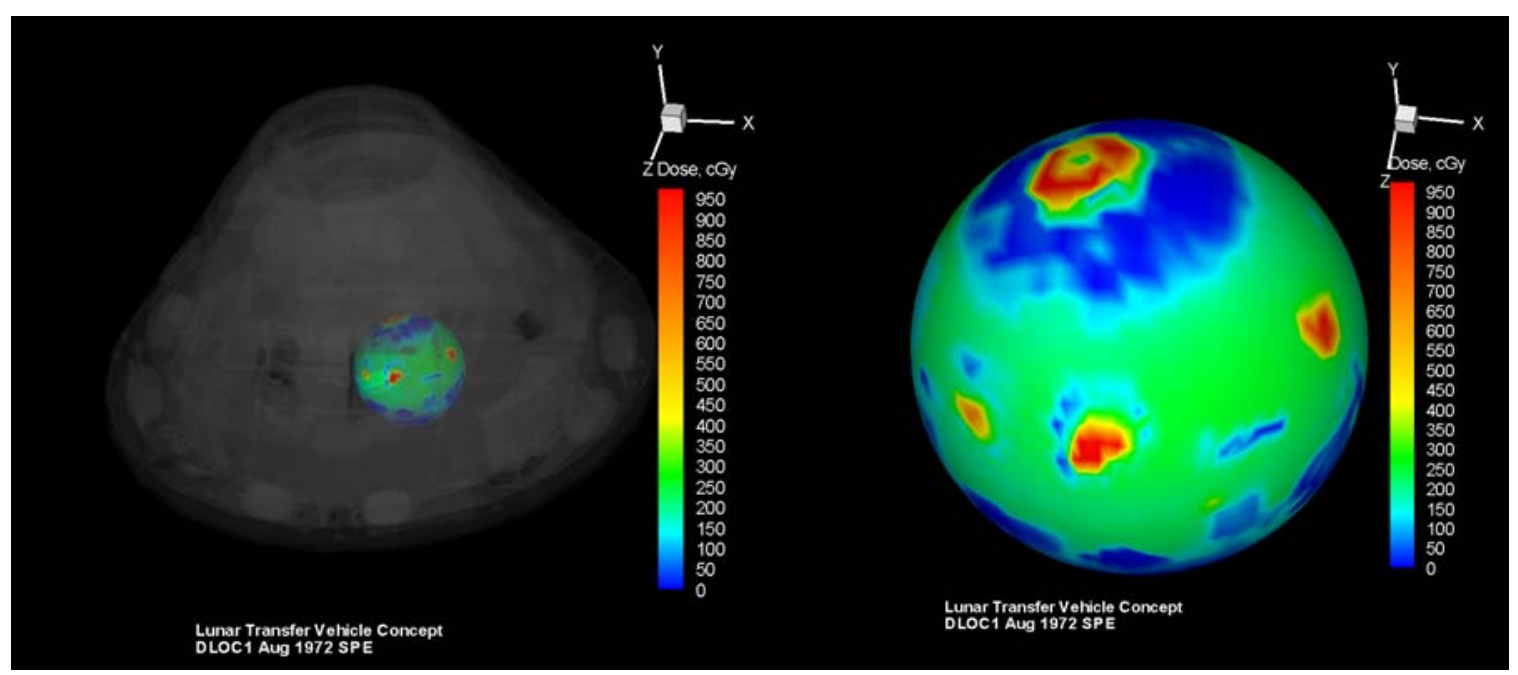

Figure 7. Visualization of detailed directional dose assessment at a dosimetry location

(DLOC1) inside a spacecraft. The spacecraft is shown in a translucent view to reveal the exact dosimetry location (left), and the same directional dose assessment is separately shown in large view (right). 


\section{Improvement of Risk Assessment from Space Radiation Exposure for Future Space Exploration Missions}

M. Y. Kim¹, A. L. Ponomarev², H. Nounu ${ }^{3}$, H. Hussein ${ }^{3}$, and F. A. Cucinotta ${ }^{4}$

${ }^{1}$ Wyle Laboratories, Inc.

2Universities Space Research Association

3University of Houston

${ }^{4}$ NASA Johnson Space Center

and

William Atwell

The Boeing Company 


\section{Approach of Risk Assessment}

- Transport properties of the shielding materials and the astronaut's body tissues: Using the NASA HZETRN/BRYNTRN code system

- Initial representative shield configurations: Assumed to be aluminum

- Space suit $\left(0.3 \mathrm{~g} / \mathrm{cm}^{2}\right)$

- Pressure vessel $\left(1.0 \mathrm{~g} / \mathrm{cm}^{2}\right)$

- Equipment room $\left(5.0 \mathrm{~g} / \mathrm{cm}^{2}\right)$

- Three sensitive organs of astronaut: Using the Computerized Anatomical Man (CAM) model

- Average skin

- Ocular lens

- Average Blood Forming Organ (BFO) 


\section{NASA Operational Radiation Protection Program}

Effective Dose $(E) \quad E=\sum_{\mathrm{T}} w_{\mathrm{T}} H_{\mathrm{T}}$

\section{Tissue Weighting Factors (ICRP, 1991)}

\begin{tabular}{|l|c|}
\hline Tissue or Organ & Tissue Weighting Factor, $\mathrm{w}_{\mathrm{T}}$ \\
\hline Gonads & 0.2 \\
\hline Bone Marrow (red) & 0.12 \\
\hline Colon & 0.12 \\
\hline Lung & 0.12 \\
\hline Stomach & 0.12 \\
\hline Bladder & 0.05 \\
\hline Breast & 0.05 \\
\hline Liver & 0.05 \\
\hline Esophagus & 0.05 \\
\hline Thyroid & 0.05 \\
\hline Skin & 0.01 \\
\hline Bone Surface & 0.01 \\
\hline Remainder* & 0.05 \\
\hline
\end{tabular}

* Additional tissues/organs: adrenals, brain, upper intestine, small intestine, kidney, muscle, pancreas, spleen, thymus, and uterus.

Effective dose $(E)$ expressed in Sv applies only to stochastic effects. 


\section{Effective Dose and BFO Dose}

behind Aluminum and Graphite Shields

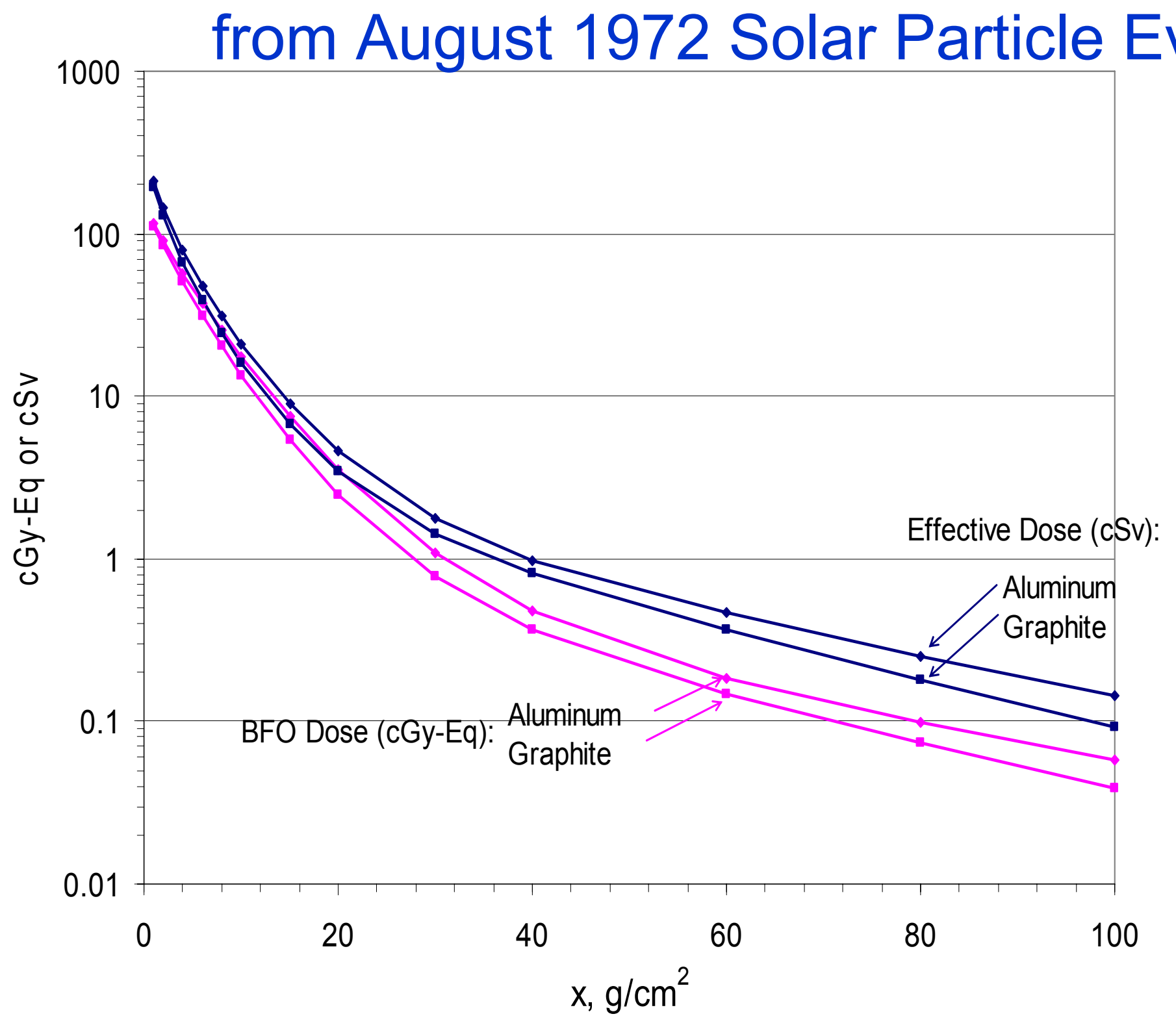




\section{Shuttle Shielding Distributions at 6 DLOCs}

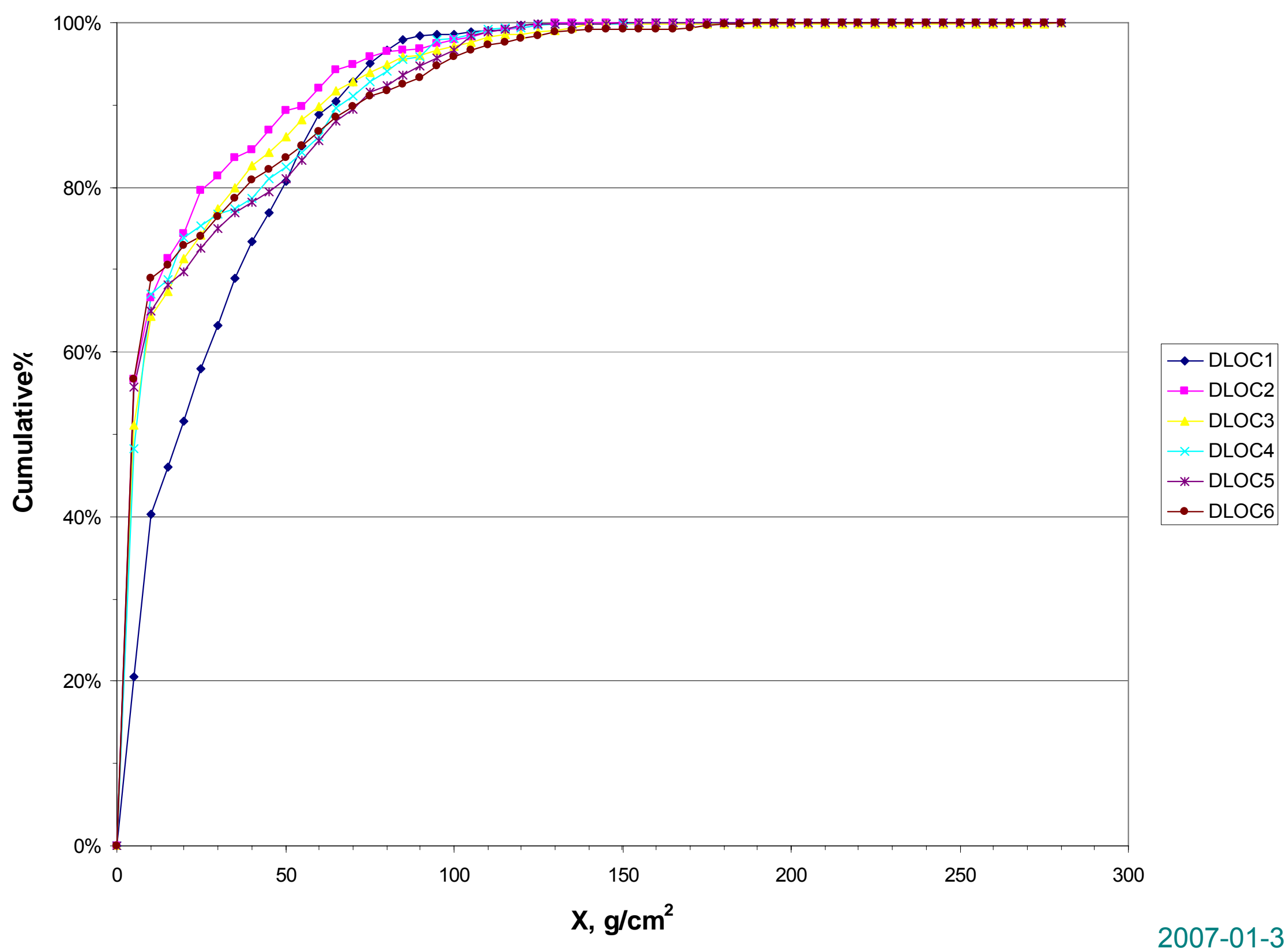




\section{Shuttle Average Thickness at 6 Locations,}

\section{Effective Dose and BFO Dose at the Average BFO site with/without Shuttle Ray Tracing}

\begin{tabular}{|lccccc|}
\hline & $\bar{X}=\frac{1}{N} \sum X_{i}$ & $\bar{E}=\frac{1}{N} \sum E\left(X_{i}\right)$ & $\bar{E}(\bar{X})$ & $\bar{B}=\frac{1}{N} \sum B\left(X_{i}\right)$ & $\bar{B}(\bar{X})$ \\
Shuttle & Ray tracing, & No ray tracing, & Ray tracing, & No ray tracing, \\
DLOC1 & 26.67 & cSv & CSv, & cGy-Eq & cGy-Eq \\
DLOC2 & 16.46 & 76.41 & 2.8 & 24.28 & 1.8 \\
DLOC3 & 19.44 & 72.60 & 8.0 & 49.62 & 7.0 \\
DLOC4 & 20.01 & 60.11 & 4.5 & 47.13 & 3.5 \\
DLOC5 & 21.08 & 73.44 & 3.9 & 41.77 & 3.4 \\
DLOC6 & 20.92 & 74.09 & 3.9 & 48.10 & 3.0 \\
\hline
\end{tabular}




\section{Current Considerations Concerning the Improvement of Risk Assessment and Protection}

$\square$ Accurate shielding distributions of space vehicle and human body organs

$\square$ Correctly aligned geometries between human and vehicle

$\square$ Detailed distribution of bone marrow sites

$\checkmark$ Head and neck, chest, abdomen, pelvis, and thighs

$\checkmark$ Age dependence of the sites

$\Rightarrow$ Visualization of risk with directional contribution provides ultimate protection for astronauts in a habitable volume. 


\section{Aluminum Equivalent Thickness for}

\section{Detailed Spacecraft Components}

$$
T_{A l-e q}=T_{M a t} \times \frac{R_{A l}(50 \mathrm{MeV})}{R_{M a t}(50 \mathrm{MeV})}=X_{M a t} \times \rho_{\text {Mat }} \times \frac{R_{A l}(50 \mathrm{MeV})}{R_{M a t}(50 \mathrm{MeV})}
$$

Where,

$T_{\text {Al-eq }}$ : Areal density of aluminum equivalent, $\mathrm{g} / \mathrm{cm}^{2}$

$T_{\text {Mat }}: \quad$ Areal density of a material, $\mathrm{g} / \mathrm{cm}^{2}$

$X_{\text {Mat }}: \quad$ Lineal thickness of a material, $\mathrm{cm}$

$R_{A l}(50 \mathrm{MeV}): \quad$ Range of $50 \mathrm{MeV}$ proton beam on aluminum, $\mathrm{g} / \mathrm{cm}^{2}$

$R_{\text {Mat }}(50 \mathrm{MeV}): \quad$ Range of $50 \mathrm{MeV}$ proton beam on a target material, g/ $/ \mathrm{cm}^{2}$

$\rho_{\text {Mat }}: \quad$ Bulk density of a material , $\mathrm{g} / \mathrm{cm}^{3}$ 


\section{Structural Distribution Model Using ProE ${ }^{\mathrm{TM}}$ Various Composition Layers for Exploratory-Class Spacecraft}

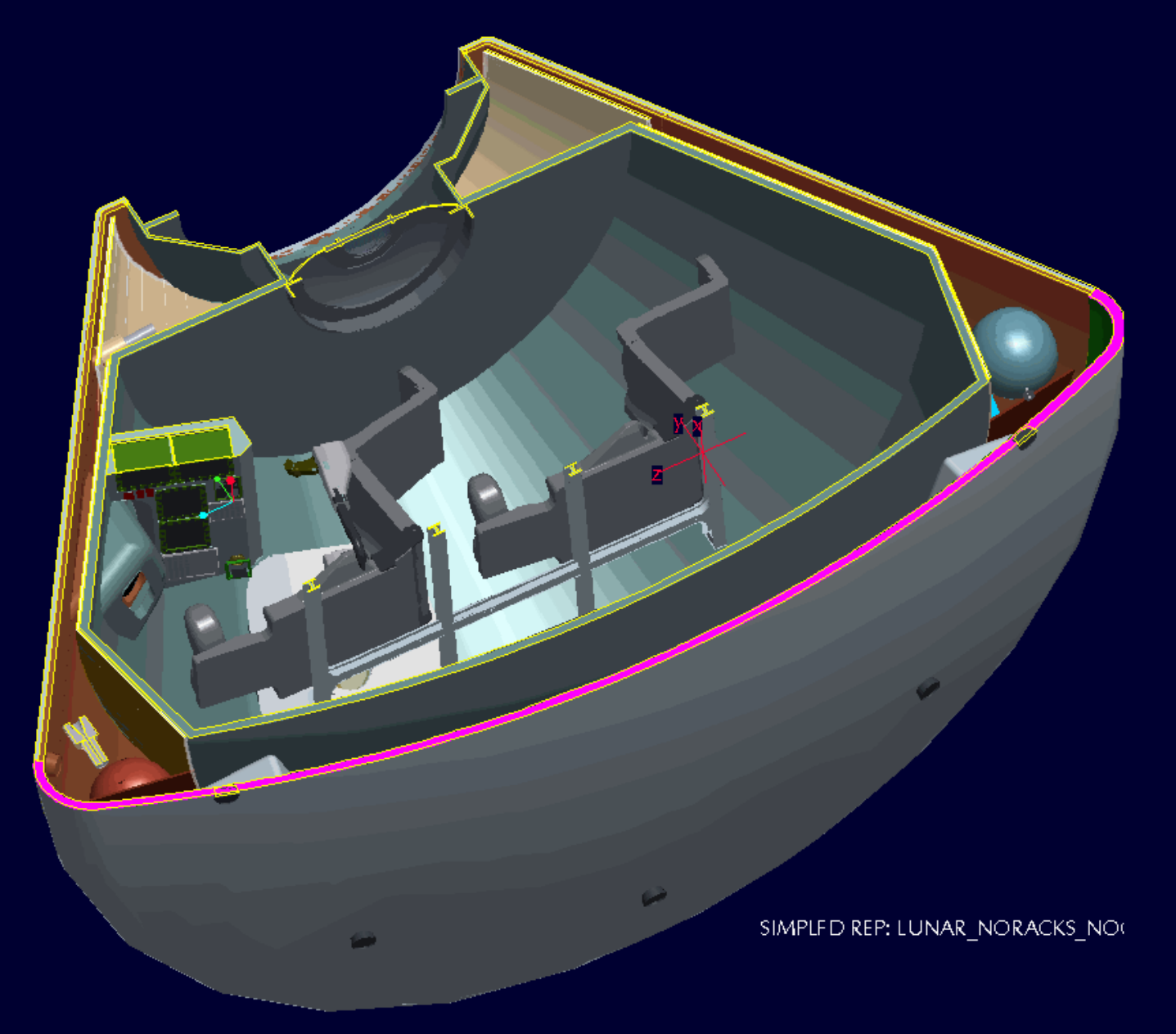




\section{Structural Distribution Model Using ProE ${ }^{\mathrm{TM}}$ Various Composition Layers for Exploratory-Class Spacecraft}

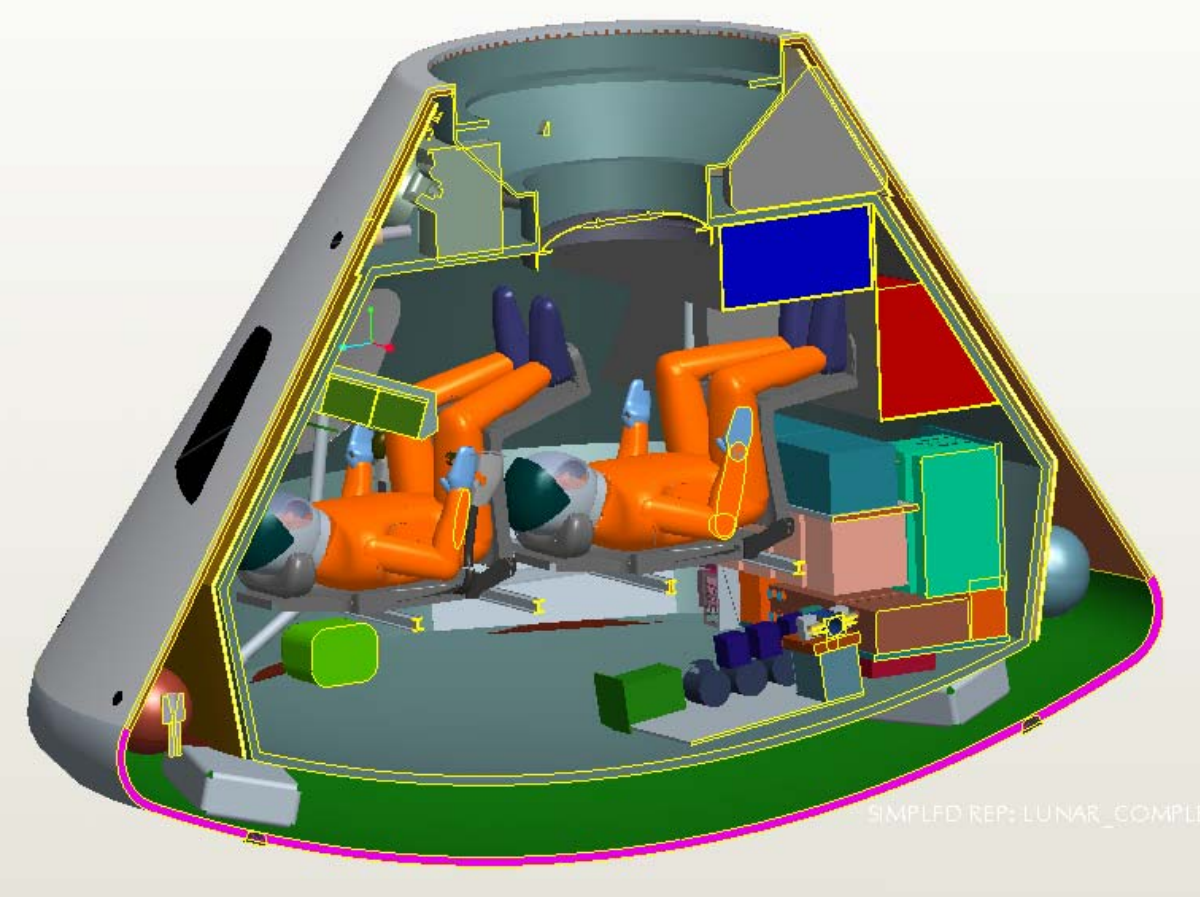


Ray Tracings at 4 DLOCs inside Spacecraft
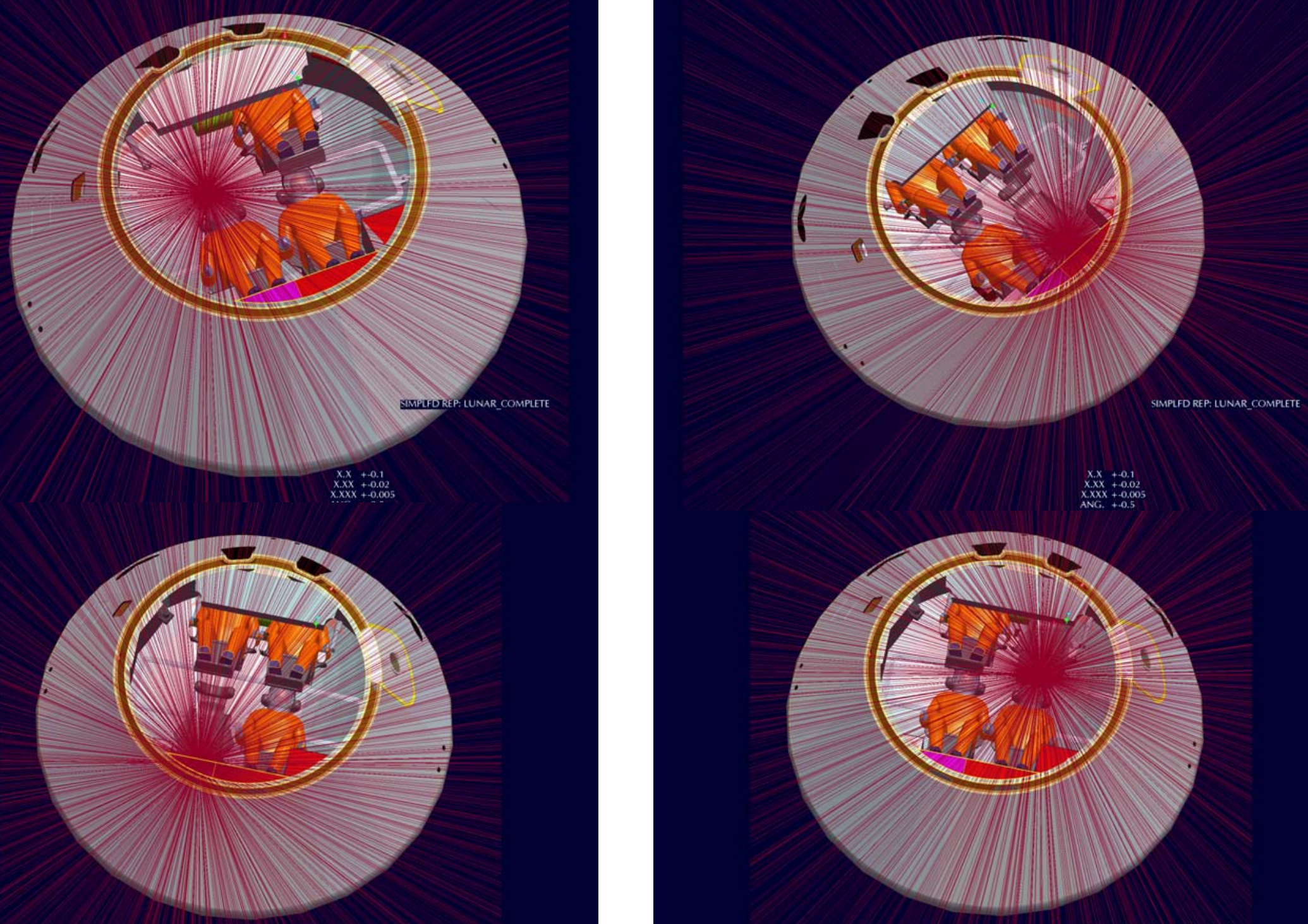
Shielding Distributions at 4 DLOCs of Spacecraft
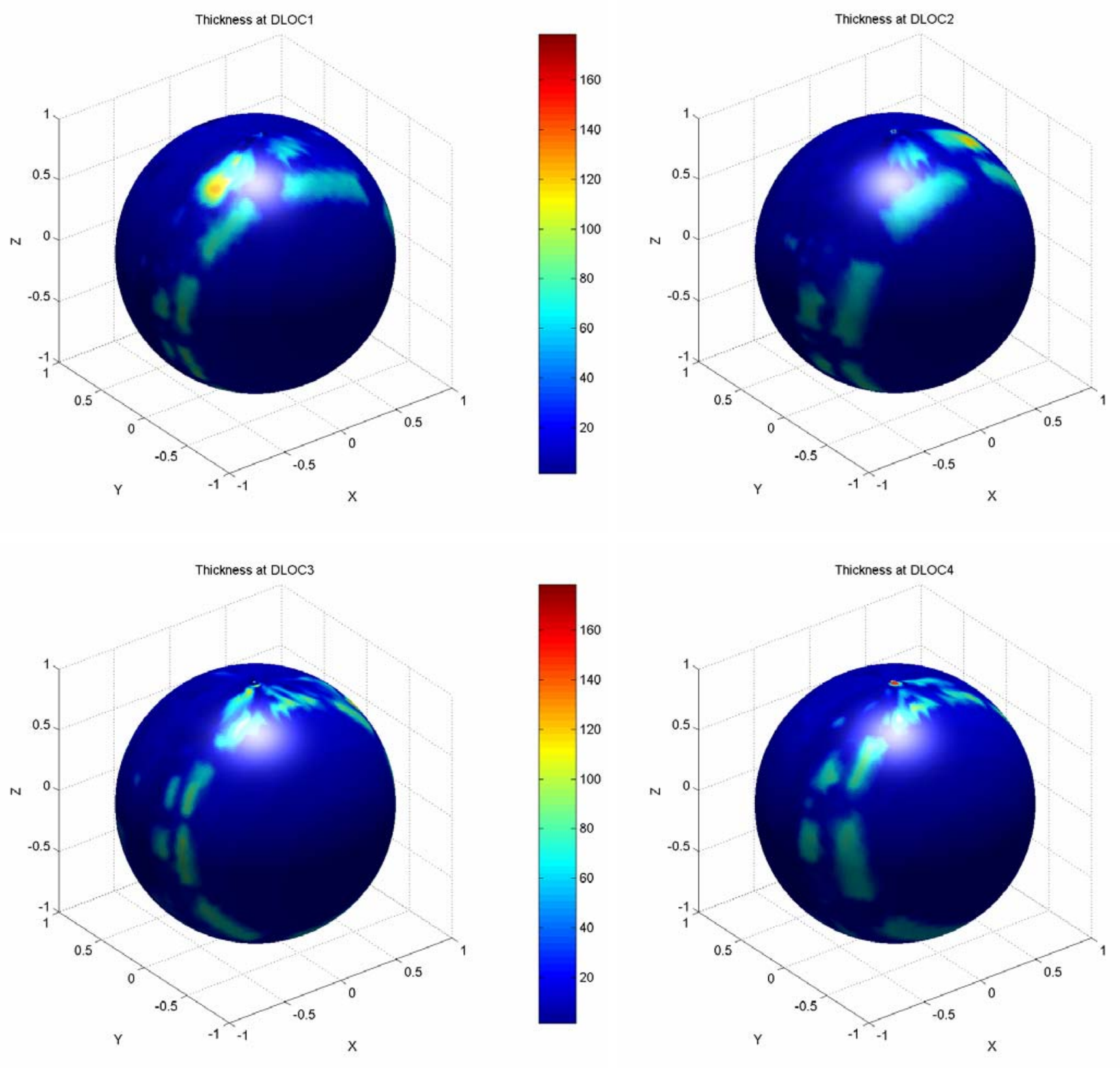


\section{Idealization of the Actual Motion of Astronaut}

Random Orientation

- Discrete number of evenly scattered rays over $4 \pi$ solid angle

- Isotropic angular distribution (for the same volume element):

$p(\mu)=$ constant

$$
\mu=\cos \theta
$$

\section{Aligned Orientation}

- A continuously distributed source rays

- Cosine angular distribution in a small interval on spherical polar coordinates (for each volume element):

$p(\mu)=\mu$

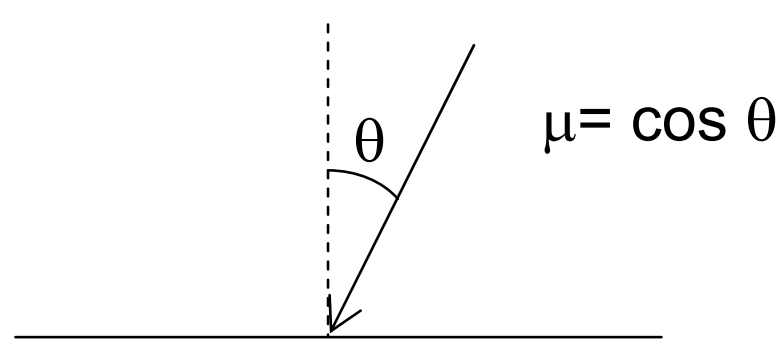




\section{Idealization of the Actual Motion of Astronauts}

$$
\begin{gathered}
\underline{\text { Random Orientation }} \\
H_{\text {organ }}=\frac{1}{N} \sum_{i=1}^{N} H_{\text {organ }}\left(X_{i}\right)
\end{gathered}
$$

where,

$N$ : the given number of rays

$X_{i}$ : a shielding amount by material composition layers at $i^{\text {th }}$ ray

$$
H_{\text {organ }}=\iint_{\theta=\frac{-\pi}{2}}^{\frac{\pi}{2}} \cos \theta d \theta d \phi H(X(\theta, \phi)+Y(\theta, \phi))
$$

where,

$\theta$ : polar angle of a ray

$\phi$ : azimuth angle of a ray

$X(\theta, \phi)$ : the integrated shielding

thickness by spacecraft of a ray

$Y(\theta, \phi)$ : the body-shielding thickness

of a ray 


\section{Dose Distributions at 4 DLOCs inside Spacecraft from 1972 SPE}


Lunar Transfer Vehicle Concept

DLOC1 Aug 1972 SPE

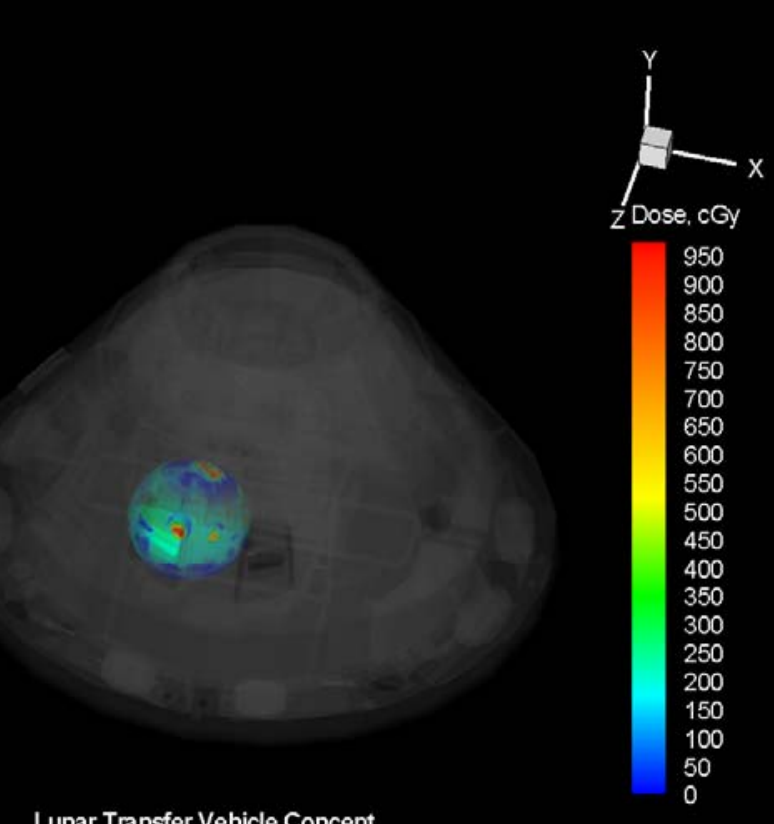

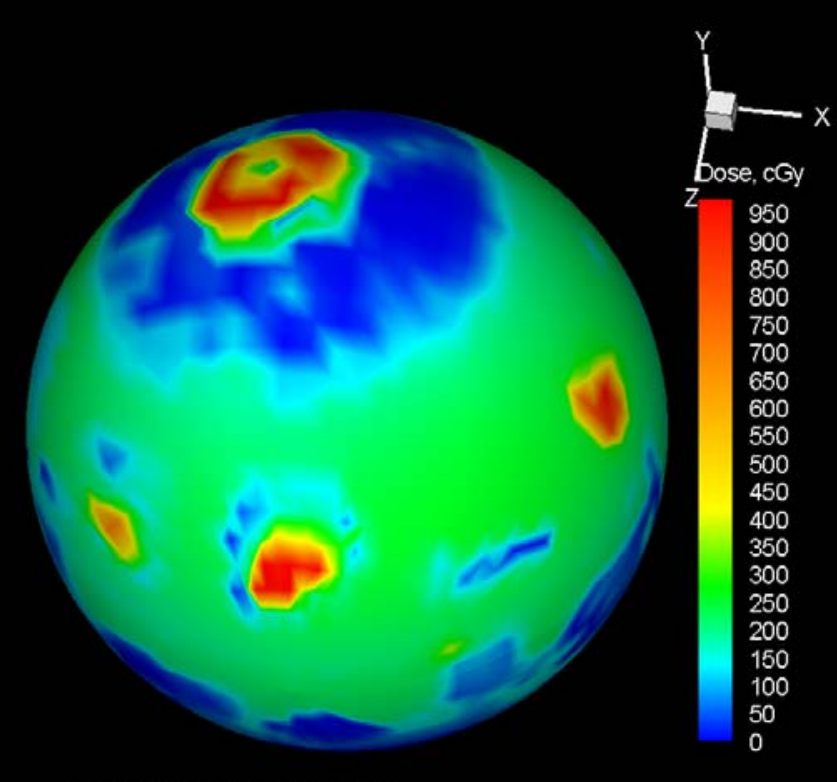

Lunar Transfer Vehicle Concept

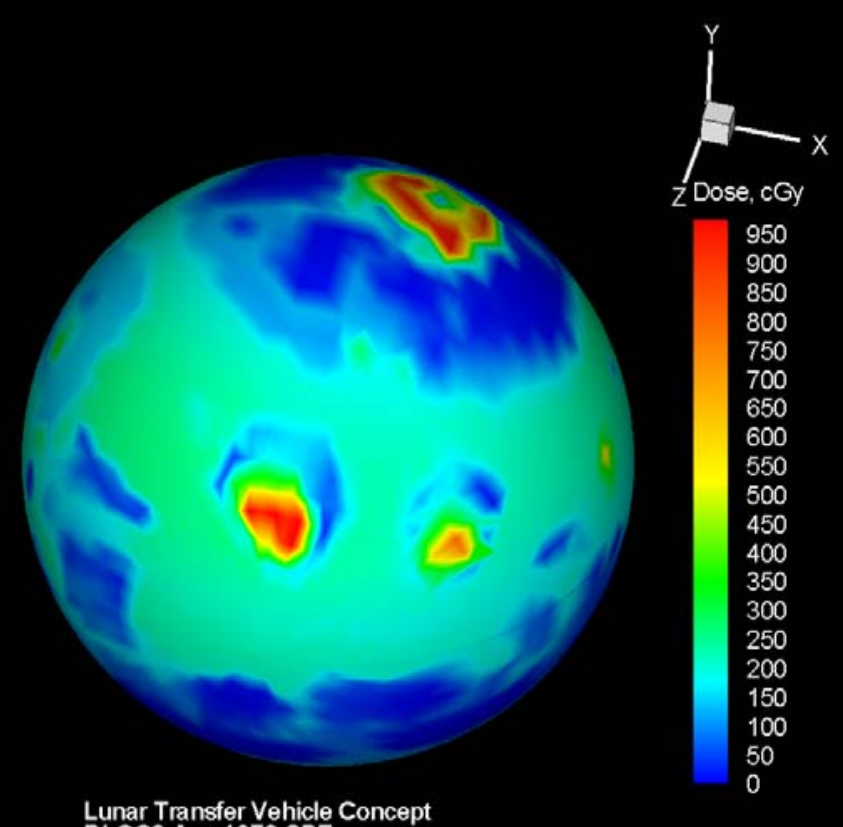

Lunar Transfer Vehicle Concept
DLOC2 Aug 1972 SPE 


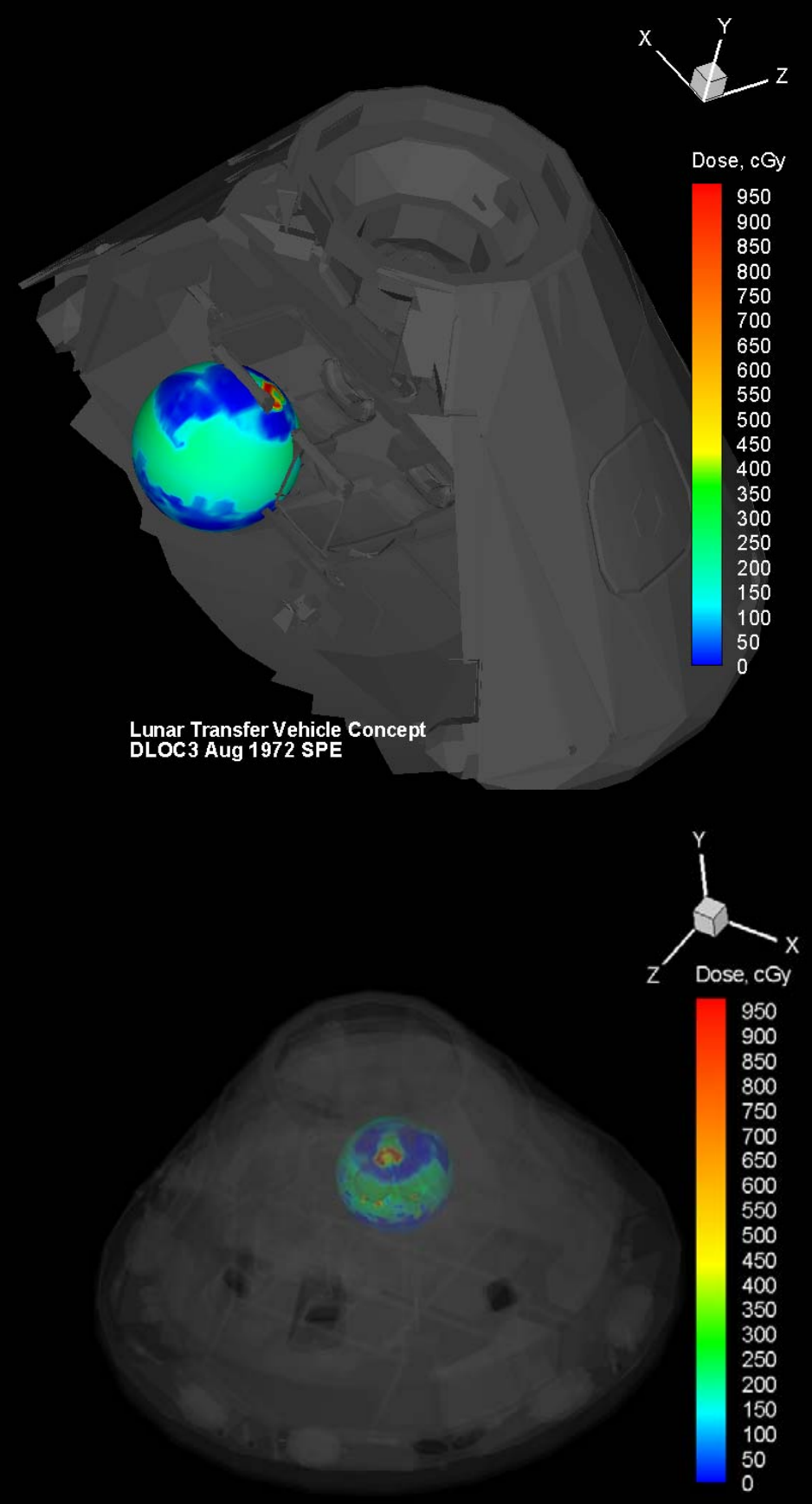

Lunar Transfer Vehicle Concept
DLOC4 Aug 1972 SPE 


\section{Organ Dose Quantities with Ray Tracing}

\begin{tabular}{|c|c|c|c|c|c|c|c|c|c|}
\hline & \multicolumn{8}{|c|}{ August 1972 SPE } \\
\hline & & \multicolumn{4}{|c|}{ Random Orientation } & \multicolumn{4}{|c|}{ Aligned Orientation } \\
\hline & & DLOC1 & DLOC2 & DLOC3 & DLOC4 & DLOC1 & DLOC2 & DLOC3 & DLOC4 \\
\hline \multicolumn{2}{|c|}{$\begin{array}{l}\text { X-coordinate, } \mathrm{cm} \\
\text { Y-coordinate, } \mathrm{cm} \\
\text { Z-coordinate }, \mathrm{cm}\end{array}$} & $\begin{array}{r}43.18 \\
119.38 \\
52.71\end{array}$ & $\begin{array}{r}-43.18 \\
119.38 \\
52.71\end{array}$ & $\begin{array}{r}40.64 \\
119.38 \\
-79.34\end{array}$ & $\begin{array}{l}-40.64 \\
119.38 \\
-79.34\end{array}$ & $\begin{array}{r}43.18 \\
119.38 \\
52.71\end{array}$ & $\begin{array}{r}-43.18 \\
119.38 \\
52.71\end{array}$ & $\begin{array}{r}40.64 \\
119.38 \\
-79.38\end{array}$ & $\begin{array}{l}-40.64 \\
119.38 \\
-79.38\end{array}$ \\
\hline \multicolumn{2}{|c|}{ Al-Eq $X_{\text {ave }}, \mathrm{g} / \mathrm{cm}^{2}$} & 15.18 & 15.08 & 15.85 & 15.33 & 15.18 & 15.08 & 15.85 & 15.33 \\
\hline \multicolumn{2}{|c|}{$X_{-\min }-X_{-\max }$} & $\begin{array}{r}0- \\
102.07\end{array}$ & $0-105.50$ & $0-83.21$ & $0-85.79$ & $0-102.07$ & $0-105.50$ & $0-83.21$ & $0-85.79$ \\
\hline \multirow{15}{*}{$\begin{array}{l}\text { CAM } \\
\text { organ } \\
\text { dose, } \\
\text { cSv }\end{array}$} & AVG SKIN & 126.61 & 121.07 & 104.08 & 108.59 & 150.92 & 135.41 & 111.45 & 114.45 \\
\hline & EYE & 86.76 & 84.36 & 73.58 & 77.06 & 89.71 & 89.94 & 81.62 & 79.72 \\
\hline & AVG BFO & 16.91 & 16.82 & 15.2 & 15.88 & 18.14 & 18.20 & 16.05 & 15.98 \\
\hline & STOMACH & 7.38 & 7.37 & 6.77 & 7.03 & 6.94 & 6.89 & 6.59 & 6.63 \\
\hline & COLON & 14.42 & 14.36 & 13.04 & 13.6 & 14.46 & 14.36 & 12.67 & 12.79 \\
\hline & LIVER & 10.37 & 10.33 & 9.41 & 9.8 & 9.43 & 9.60 & 8.92 & 9.23 \\
\hline & LUNG & 12.16 & 12.12 & 11.04 & 11.5 & 12.09 & 11.61 & 11.30 & 10.73 \\
\hline & OESOPHAGUS & 11.61 & 11.57 & 10.54 & 10.98 & 11.25 & 10.78 & 10.52 & 9.93 \\
\hline & BLADDER & 7.54 & 7.53 & 6.9 & 7.17 & 7.64 & 7.25 & 6.98 & 6.84 \\
\hline & THYROID & 18.39 & 18.31 & 16.55 & 17.28 & 18.55 & 18.15 & 16.47 & 16.79 \\
\hline & CHEST & 72.23 & 70.58 & 61.85 & 64.83 & 74.88 & 73.95 & 67.60 & 66.37 \\
\hline & GONADS & 35.27 & 34.74 & 30.76 & 32.24 & 37.72 & 32.64 & 31.19 & 27.74 \\
\hline & FRONT BRAIN & 29.54 & 29.32 & 26.31 & 27.53 & 28.72 & 27.60 & 25.32 & 25.32 \\
\hline & MID BRAIN & 16.2 & 16.15 & 14.68 & 15.3 & 15.52 & 15.56 & 14.05 & 15.03 \\
\hline & REAR BRAIN & 28.93 & 28.72 & 25.79 & 26.98 & 27.49 & 27.96 & 24.98 & 27.84 \\
\hline \multicolumn{2}{|c|}{ Point dose eq, cSv } & 254.68 & 242.74 & 207.92 & 216.83 & 253.48 & 241.76 & 205.76 & 211.88 \\
\hline
\end{tabular}




\section{BFO Locations}

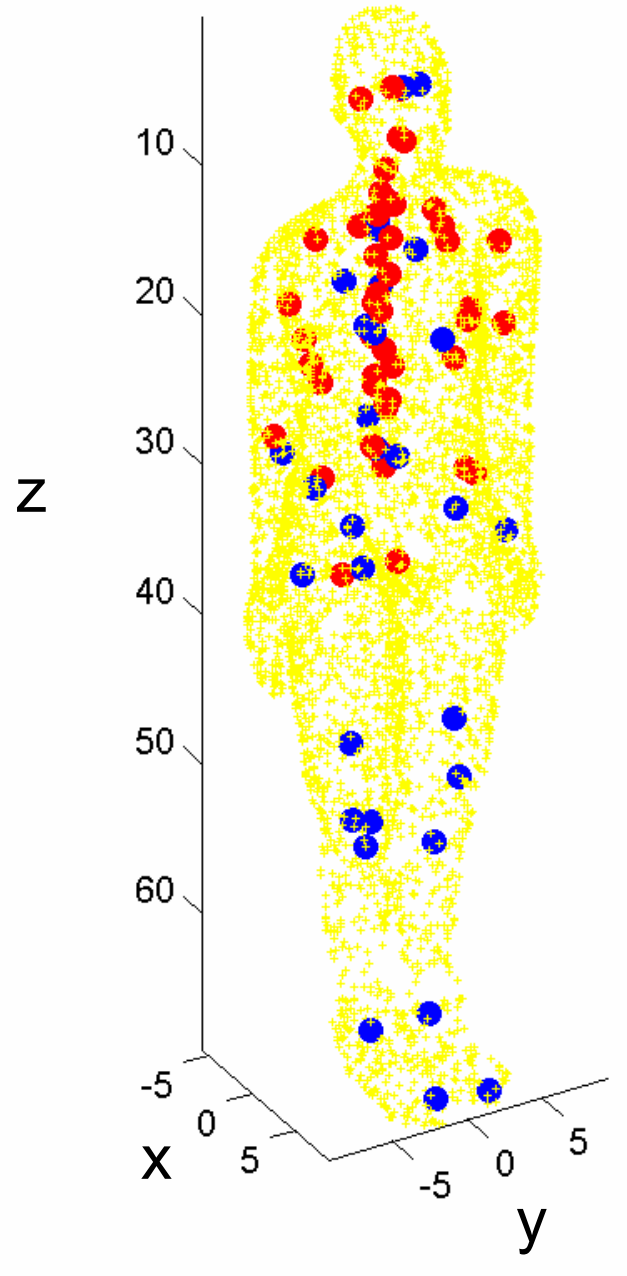

- 32-location set

- 50-location set 


\section{Body Regions for BFO Locations and}

\section{Active Marrow Distributions in Adult (Cristy, 1981)}

\begin{tabular}{|c|l|l|c|}
\hline Region Number & Body Region & Location & Marrow Distribution \\
\hline 1 & Head and Neck & $\mathrm{Z}=$ up to $11.34 "$ & $12.2 \%$ \\
\hline 2 & Chest (Upper Torso) & $\mathrm{Z}=11.34^{\prime \prime}$ to $15.6^{\prime \prime}$ & $26.1 \%$ \\
\hline 3 & Abdomen (Mid Torso) & $\mathrm{Z}=15.6^{\prime \prime}$ to $27.0^{\prime \prime}$ & $24.9 \%$ \\
\hline 4 & Pelvis (Lower Torso) & $\mathrm{Z}=27.0^{\prime \prime}$ to $36.7^{\prime \prime}$ & $33.4 \%$ \\
\hline 5 & Thighs (Upper Legs) & $\mathrm{Z}=36.7^{\prime \prime}$ to $52.3^{\prime \prime}$ & $3.4 \%$ \\
\hline 6 & Lower Legs & $\mathrm{Z}=52.3^{\prime \prime}$ to $70^{\prime \prime}$ & n/a \\
\hline 7 & Arms & $\begin{array}{l}\text { Y<-6.9" for right arm; } \\
\text { Y>6.9" for left arm }\end{array}$ \\
\hline
\end{tabular}




\section{BFO Dose from August 1972 SPE at DLOC1}

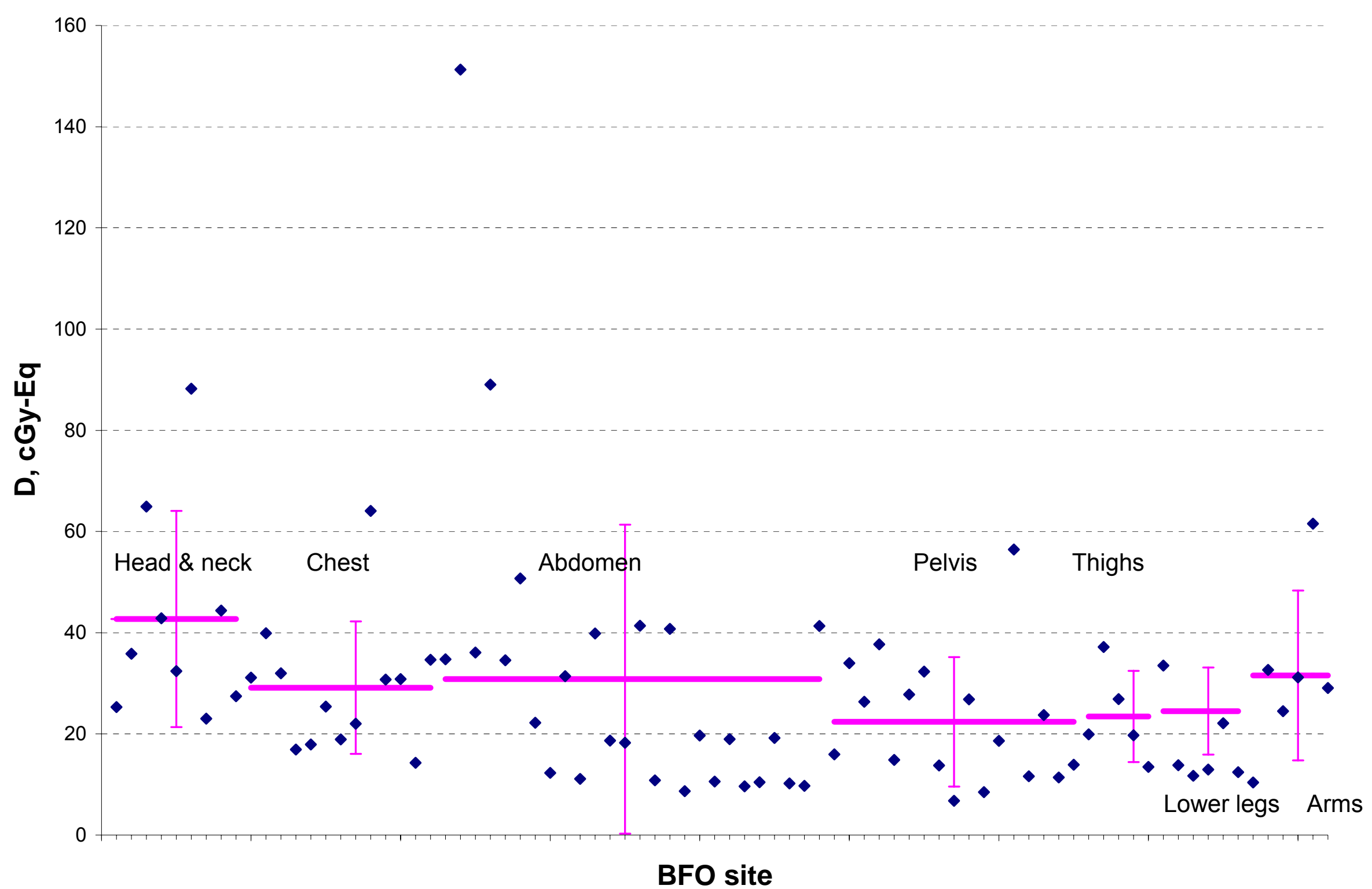




\section{Concluding Remarks}

- Accurate shielding distributions are obtained from SRP (Space Radiation Program) ray tracer and geometries between human and vehicle are correctly aligned: $>$ There are still hot spots for sensitive site of tissue/organ inside a spacecraft with overall thick enough shielding configuration.

Detailed distribution of bone marrow sites are considered: $>$ Head and neck, chest, abdomen, pelvis, and thighs

$\Rightarrow$ Detailed distribution of directional risk assessment can guide the ultimate protection for risk mitigation inside a habitable volume during future exploration missions. 


\section{Future Work for Improvement of Risk Assessment and Protection}

$\square$ Age- and gender-related tissue weighting factors must be defined.

Modified transport codes are needed with vehicleproduced secondary neutrons.

Improved environmental projection model is needed for mission planning.

Transport properties with their atomic properties should be accounted for each detailed structural components (parallel processing).

Local shielding approaches including astronaut orientation optimization will be made. 


\section{References}

1. Wilson, J. W., Badavi, F. F., Cucinotta, F. A., et al., HZETRN: Description of a free-space ion and nucleon transport and shielding computer program.

NASA TP-3495, 1995.

2. Cucinotta, F. A., Wilson, J. W., Badavi, F. F., Extension to the BRYNTRN code to monoenergetic light ion beams. NASA TP-3472, 1994.

3. Billings, M.P., Yucker, W.R. The computerized anatomical man (CAM) model. NASA CR-134043, 1973.

4. ICRP, 1990 Recommendations of the International Commission on Radiological Protection. ICRP Publ. 60, Pergamon Press Inc., 1991.

5. King, J. H., August 1972 SPE spectra, unpublished records of a NASA workshop, correspondence dated October 24, 1972, from J. H. King (NASA Goddard Space Flight Center) to A. C. Hardy (NASA Johnson Space Center).

6. Cristy, M., Active bone marrow distribution as a function of age in humans. Phys. Med. Biol., Vol. 26, No. 3, 389-400, 1981.

7. Pro/ENGINEER ${ }^{\circledR}$ Wildfire 2.0, Parametric Technology Corporation, March 2004. 